\title{
REDUÇÃO DE MEDIDAS ABDOMINAIS DE MULHERES JOVENS SUBMETIDAS Á UM TREINAMENTO FISICO POR MEIO DO MÉTODO PILATES ${ }^{\circledR}$
}

\author{
Fernanda Souza Silva ${ }^{1}$ \\ Fernanda Cortez Moraes ${ }^{2}$ \\ Luís Henrique Sales Oliveira ${ }^{3}$ \\ Pâmela Camila Pereira ${ }^{4}$
}

\begin{abstract}
Resumo: Uma das principais preocupações de mulheres jovens é a lipodistrofia, e o método Pilates ${ }^{\circledR}$ ajuda a diminuir a adiposidade através de exercícios que priorizam o fortalecimento da musculatura do "power house". Objetivo: Analisar a influência do treinamento físico por meio do Método Pilates ${ }^{\circledR}$ na redução de medidas abdominais de mulheres jovens. Metodologia: Trata-se de um estudo transversal, intervencional, quantitativo e de centro único, amostra foi composta por 3 mulheres saudáveis, entre 18 e 23 anos, que realizaram exercícios do Método Pilates ${ }^{\circledR}$, avaliadas antes e após 10 sessões. Resultados: 0 método Pilates ${ }^{\circledR}$ foi eficaz na redução significativa das medidas abdominais. Discussão: O método Pilates® é considerado uma importante ferramenta para melhorar a aparência física pois há melhora da força abdominal, fortalecimento da musculatura e redução da lipodistrofia. Conclusão: O Método Pilates®é capaz de reduzir medidas abdominais por meio dos exercícios propostos.
\end{abstract}

Palavras-chave: Pilates; Mulheres; Lipodistrofia.

\footnotetext{
1 Graduanda de Fisioterapia, Brasil. E-mail: ffss07@yahoo.com.br.

2 Docente de Fisioterapia, Brasil. E-mail: fernandacortezmoraes@yahoo.com.br.

${ }^{3}$ Docente de Fisioterapia, Brasil. E-mail: Ihfisio@yahoo.com.br.

4 Docente de Fisioterapia, Brasil. E-mail: pam_milaf@yahoo.com.br.
} 